\title{
Synthesis and Characterizations of Hydrophilic pHEMA Nanoparticles via Inverse Miniemulsion Polymerization
}

(Sintesis dan Pencirian Zarah Nano Hidrofil pHEMA melalui Pempolimeran Miniemulsi Songsang)

\author{
ZALIKHA ISMAIL \& NOOR ANIZA HARUN*
}

\begin{abstract}
This study highlights on the development of hydrophilic polymer nanoparticles prepared via inverse miniemulsion polymerization, a robust technique to prepare hydrophilic and aqueous-soluble polymeric nanoparticles. 2-hydroxyethyl methacrylate (HEMA) is excellent candidate for homo-polymerization due to its biocompatibility and biodegradability characteristic with high hydrophilicity properties. The influence of synthesis parameters including the effects of sonication time ranging from 10 - 30 min and sonication amplitude up to 60\% towards the particles size and morphology of pHEMA nanoparticles are investigated. The formation of pHEMA nanoparticles are confirmed by Fourier Transform Infrared (FTIR). The morphology of polymer nanoparticles has been determined using Scanning Electron Microscope (SEM) and Transmission Electron Microscopy (TEM). Dynamic light scattering (DLS) indicates the mean diameters of pHEMA nanoparticles were in a range of $100-200 \mathrm{~nm}$. The hydrophilic polymer nanoparticles obtained are expected to facilitate in the fabrication of inorganic-polymer composite nanoparticles especially in biological applications.
\end{abstract}

Keywords: HEMA; hydrophilic; inverse miniemulsion; nanoparticles

\section{ABSTRAK}

Kajian ini menonjolkan pembangunan zarah nano polimer dengan ciri hidrofil yang lebih baik yang disediakan melalui pempolimeran miniemulsi songsang, suatu teknik yang teguh untuk menyediakan zarah nano polimer hidrofil dan larut akueus. 2-hidroksi metakrilat (HEMA) adalah bahan yang sangat baik untuk pempolimeran-homo kerana sifat biokeserasian dan biodegradasi dengan sifat hidrofil yang tinggi. Pengaruh parameter sintesis termasuk kesan masa sonikasi antara 10 - 30 min dan amplifikasi sonikasi sehingga $60 \%$ ke arah saiz zarah dan morfologi zarah nano pHEMA dikaji. Pembentukan zarah nano pHEMA disahkan oleh Spektroskopi Inframerah Transformasi Fourier (FTIR). Morfologi zarah nano polimer telah ditentukan menggunakan Mikroskop Elektron Imbasan (SEM) dan Mikroskop Elektron Transmisi (TEM). Penyebaran cahaya dinamik (DLS) menunjukkan diameter purata zarah nano pHEMA berada dalam lingkungan 100 - $200 \mathrm{~nm}$. Zarah nano polimer hidrofil yang diperoleh dijangka memudahkan dalam fabrikasi zarah nano komposit polimer-bukan organik terutamanya dalam aplikasi biologi.

Kata kunci: HEMA; hidrofil; pempolimeran songsang; zarah nano

\section{INTRODUCTION}

Polymer-based materials appeal to be very convenient materials for biomedical applications due the fact of ease manufacturing using countless techniques with great stability (Rao \& Geckeler 2011). Polymeric nanoparticles (PNPs) have been utilized in a vast range of applications including drug delivery (Bajpai et al. 2008; Oh et al. 2009), medical imaging (Chen \& Yin 2014), tissue engineering (Muthiah et al. 2013), microfluids (Han et al. 2016) and nanotechnology purposes. Since polymerbased materials can be tailored into specific requirements and applications, it is essentials for PNPs to possess specific criteria for application in biomedical science such as non-toxicity, non-immunogenic, biocompatible, biodegradable and improved water solubility (Srivastava et al. 2016). Biodegradable PNPs can be synthesized from natural or synthetic polymer. Natural biodegradable polymers are usually derived from protein-based polymer or polysaccharide while synthetic biodegradable polymers are usually from polyester, polyanhydride and polyamide group (Gavasane \& Pawar 2014). Synthetic biodegradable PNPs are more favorable on account of ease of modification on functional polymer chain group into specific requirements and the ability of synthetic polymer to stimulate any immune response (Tian et al. 2012)

Developing biodegradable PNPs require specific selection of monomer depending on the purpose of application. Poly(2-hydroxyethylene methacrylate) (pHEMA) attracts much attention in biomaterials science due to its biocompatibility and water-swellable polymer effect (Elbert 2011). Since 1995, Mirzadeh et al. (1995) have utilized grafted HEMA monomer on the surface of ethylene-propylene rubber (EPR) to improve tissue compatibility. HEMA has been manipulated to fabricate with silicon substrate film in developing human cell growth film for biotechnology purposes (Bodas et al. 
2005). On account of their outstanding properties of non-toxic, swelling ability and maintaining the liquid content during swollen state, pHEMA also has been utilized in drug delivery system. Gulsen and Chauhan (2005) proved that pHEMA hydrogels is a potential carrier for ophthalmic drug delivery vehicles and have been widely used in contact lenses production. pHEMA has shown great versatility to be incorporated with wide range of drugs or materials with minimal toxicity and can be utilized as universal candidates for biomedical and pharmaceutical applications.

When considering synthetic approaches to prepare PNPS, various techniques can be employed for instance precipitation, suspension (Gao et al. 2013), dispersion (Richez et al. 2013), emulsion and miniemulsion polymerization (Faridi-Majidi et al. 2006; Harun et al. 2011; Yildiz \& Landfester 2008). The selection of suitable preparation method for PNPs is crucial, for instance, a polymeric system that is developed for a specific application in the biomedical or environmental field should be completely free from any additives or reactants (Pandey et al. 2013), and must meet biocompatible and biodegradable credentials. Additionally, the PNPs must also have the ability to be dissolved in aqueous medium or to be obtained from hydrophilic types of polymer nanoparticles in order to broaden their potentiality in biological and medical applications (Ghosh 2000).

Inverse miniemulsion polymerization in particular has become an attractive method to prepare hydrophilic PNPs (Cao et al. 2013; Xu et al. 2008). Inverse miniemulsion polymerization or also known as waterin-oil (W/O) miniemulsion consists of small, stable and narrowly particles size with diameter within $50-500$ $\mathrm{nm}$ (Capek 2010). Inverse miniemulsion polymerization utilized water soluble monomer and can be employed to encapsulate hydrophilic or hydrophobic liquids and solid within polymeric shell, where, found to be suitable for biomedical applications as marker or drug delivery system (Oh et al. 2006).

Several researchers have discussed about the preparation of hydrophilic polymer nanoparticles via inverse miniemulsion polymerization. The synthesis of block copolymers poly(ethylene oxide)-poly(2hydroxyl methacrylate) (PEO-PHEMA) nanoparticles via inverse miniemulsion polymerization was successfully investigated (Oh et al. 2007). From the findings, stable PHEMA nanoparticles were only obtained by using polymer surfactants (poly(ethylene-co- butylene)blockpoly(ethylene oxide)) in comparison to Span 80 and Brij 35 surfactants. Moreover, the incorporation of PEO-functionalized bromoisobutyrate macroinitiators (PEO-Br) has caused PEO-containing PHEMA di- and triblock copolymers nanoparticles to form.

$\mathrm{Xu}$ et al. (2004) has successfully synthesized hydrophilic magnetic nanoparticles via inverse miniemulsion polymerization technique. The nanosized iron oxide particles encapsulated by polyacrylamide proved to be well dispersed in water and has potentiality as a candidate for biological application. Novel interpenetrating polymer network (IPN) nanogels composed of poly(acrylic acid) and gelatin were synthesized in one pot inverse miniemulsion polymerization technique (Koul et al. 2011). These IPN nanogels expected to be utilized as targeted drug delivery system for solid tumors treatment. Despite that, inverse miniemulsion polymerization also has been employed in the preparation of nanogels from natural polymer. Sarika et al. (2015) synthesized potential nanogels system for drug and gene delivery system from alginic aldehyde and gelatin through inverse miniemulsion polymerization technique.

Recently hydrophilic poly(N-vinylpyrrolidone) (PNVP) nanoparticles were successfully synthesized via the inverse miniemulsion method. In this work, the effect of molar ratio of water as aqueous phase towards particle size, size distribution and the morphological structure of PNVP nanoparticles were studied. The results suggested that increasing the molar ratio of water up to $1: 4$ with constant monomer molar ratio causes the increment of particle size, yet a higher molar ratio of water shows a decreasing trend of particle size but with larger size distribution. In addition, the difference molar ratio of water could also affect the physical appearance of PNVP nanoparticles and enhance the solubility of the nanoparticles in aqueous media (Ismail et al. 2017).

In this work, pHEMA nanoparticles were synthesized via inverse miniemulsion polymerization method. The influence of synthesis parameters including the effect of sonication time and amplitude towards the particle size and morphology of pHEMA nanoparticles were investigated. The development of hydrophilic pHEMA nanoparticles can be utilized further in the fabrication of inorganic-polymer composite nanoparticles especially in medical and biological applications.

\section{MATERIALS AND METHODS}

\section{MATERIALS}

2-hydroxyethylene methacrylate (HEMA) monomer was purchased from Merck and used as received. Sorbitan monooleate (Span 80, extra pure reagent) was purchased from Nacalai Tasque and used as received without further purification. Cyclohexane (A.R grade) was purchased from $\mathrm{R} \& \mathrm{M}$ Chemicals and used as received. $\alpha, \alpha-$ Azobisisobutyronitrile (AIBN) were also purchased from R\&M Chemical and recrystallized twice from methanol. Distilled water was used throughout the experiment.

\section{PREPARATION OF PHEMA NANOPARTICLES VIA INVERSE MINIEMULSION POLYMERIZATION}

Water-in-oil miniemulsion polymerization was performed in a two phase system, consisting of dispersed monomer phase and non-polar continuous phase. The dispersed monomer phase employed HEMA monomer $(0.93 \mathrm{~mL})$ 
which was dissolved in distilled water $(0.50 \mathrm{~mL})$. Whilst, the non-polar continuous phase consisted of non-ionic surfactant, Span 80 (0.09 M) dissolved in cyclohexane $(16.0 \mathrm{~mL})$. The monomer solution was added into the non-polar phase and the mixture was pre-emulsified under vigorous stirring. After $1 \mathrm{~h}$, the inverse miniemulsion system was generated by ultrasonication of the emulsion solution for certain amplitudes and times with a high intensity ultrasonic processor (Fisher Scientific Sonic Dismembrator Model 705 tapered microtips, 700W). During the sonication, the emulsion mixture was icedcooled to avoid any unwanted polymerization due to heating of the sample. The resulting inverse miniemulsion was then transferred into a three-neck round bottom flask equipped with a condenser and $\mathrm{N}_{2}$ inlet. The polymerization was performed under $\mathrm{N}_{2}$ at $70^{\circ} \mathrm{C}$ and initiated by addition of oil soluble initiator, $\operatorname{AIBN}(0.01 \mathrm{M})$. The polymerization was completed after $3 \mathrm{~h}$ and the reaction was terminated by cooling to room temperature.

\section{CHARACTERIZATIONS OF POLYMER NANOPARTICLES}

Dynamic Light Scattering (DLS) Particle size and particle size distribution of the polymer nanoparticles were performed by dynamic light scattering (DLS) (Zetasizer Nano ZS, Malvern Instrument) at $25 \pm 0.1^{\circ} \mathrm{C}$ with scattering angle of $90^{\circ}$. The emulsion of polymer nanoparticles $(0.5 \mu \mathrm{L})$ was diluted with cyclohexane $(10 \mathrm{~mL})$ and the dispersion was sonicated for $5 \mathrm{~min}$. The sample solutions were then placed in a glass cuvette and measurements were performed five times.

Fourier Transform Infrared Spectroscopy (FTIR) FTIR spectra of polymer nanoparticles were recorded using KBR pellets by Perkin Elmer Spectrum 100 with sampling range from 450 to $4000 \mathrm{~cm}^{-1}$ and 16 times of scan number.
Scanning Electron Microscopy (SEM) The polymer nanoparticles samples were mounted on SEM holder and coated with gold by Auto Fine Coater (JEOL) to prevent accumulation of electrostatic charge on the surface of samples. The morphology of polymer nanoparticles was observed by SEM (JEOL, JSM6360LA, Japan) at 15 - $20 \mathrm{kV}$ accelerating voltage.

Transmission Electron Microscopy (TEM) Samples for TEM were prepared by drop casting of diluted polymer solution on carbon-coated copper grid and the samples left to dry overnight. TEM measurements were performed at ambient temperature using Tecnai G2 Spirit Biotwin (USA) at $120 \mathrm{kV}$.

\section{SOLUBILITY TEST}

Polymer nanoparticles $(5 \mathrm{mg}$ ) were dissolved in distilled water $(10 \mathrm{~mL})$ and left at room temperature within 2 weeks for observation with no applying sources of energy.

\section{RESULTS AND DISCUSSION}

\section{PREPARATION OF PHEMA NANOPARTICLES VIA INVERSE MINIEMULSION POLYMERIZATION}

Table 1 summarizes the amplitudes and time of sonication for inverse miniemulsion polymerization of pHEMA nanoparticles.

The sonication amplitudes range from 10\%-60\% whilst the sonication times were observed within 10 to 30 min. It is noteworthy to mention that pHEMA nanoparticles were obtained in the form of emulsion solution after polymerization except for pHEMA_8 and pHEMA_12 where both of the samples were attained in the form of solid powder after polymerization.

TABLE 1. Mean particle diameter $\left(\mathrm{D}_{\mathrm{h}}\right)$ and polydispersity index (PDI) for a series of pHEMA nanoparticles obtained at different sonication amplitudes and times

\begin{tabular}{lcccc}
\hline Samples & $\begin{array}{c}\text { Amplitude } \\
(\%)\end{array}$ & $\begin{array}{c}\text { Time } \\
(\text { Min })\end{array}$ & $\begin{array}{c}\text { D } \\
(\mathrm{nm})\end{array}$ & PDI \\
\hline pHEMA_1 & 10 & 10 & 113 & 0.238 \\
pHEMA_2 & 20 & 10 & 128 & 0.341 \\
pHEMA_3 & 30 & 10 & 105 & 0.170 \\
pHEMA_4 & 40 & 10 & 209 & 0.684 \\
pHEMA_5 & 50 & 10 & 101 & 0.131 \\
pHEMA_6 & 50 & 15 & 131 & 0.224 \\
pHEMA_7 & 50 & 20 & 242 & 0.349 \\
pHEMA_8 & 50 & 30 & 46 & 0.570 \\
pHEMA_9 & 60 & 10 & 125 & 0.190 \\
pHEMA_10 & 60 & 15 & 144 & 0.295 \\
pHEMA_11 & 60 & 20 & 100 & 0.164 \\
pHEMA_12 & 60 & 30 & 742 & 0.636 \\
\hline
\end{tabular}




\section{PARTICLE SIZE DISTRIBUTIONS}

The particles sizes and size distribution (PDI) of the pHEMA nanoparticles were measured by DLS (Table 1 and Figures 1 to 3 ). Figure 1 depicts the particle size and PDI of pHEMA nanoparticles obtained at different sonication amplitudes prepared at $10 \mathrm{~min}$ of sonication time.

The particle size of pHEMA_1 - pHEMA_5 which prepared at different sonication amplitude ranging from $10-60 \%$ were fluctuated throughout 10 min sonication time (Figure 1). In addition, the distribution of pHEMA nanoparticles showed narrower distribution, as indicated by the decreasing of PDI values from 0.341 (pHEMA_2) to 0.131 (pHEMA_5) when the sonication amplitude increase from $20 \%$ to $50 \%$ at $10 \mathrm{~min}$ of sonication. The possible explanation for this observation maybe associated to the input energy of sonication device to produce monomer droplets through ultrasonic wave, where, higher energy input will produce smaller droplets with better dispersity. However, pHEMA_4 shows an exceptional increasing of particle size and PDI value. It can be assumed that, sonication at $40 \%$ amplitude for 10 min possibly generates nanoparticles with the smallest size. Low stability of smaller nanoparticles along with Ostwald ripening phenomenon may possibly trigger the individual particles to coalescence and forming aggregation and consequently affecting the particle size and PDI value of pHEMA_4. Increasing of sonication energy up to 60\% amplitude (pHEMA_9) gives a slightly increase of particle size and PDI value which might be due to excessive of break-up energy that leads to small coagulation.

Variation of sonication time at $50 \%$ and $60 \%$ sonication amplitude were performed for better understanding in correlation between sonication time and sonication input energy towards particles size and its distribution. Theoretically, increasing sonication time will prolong the exposure of inverse emulsion solution in the ultrasound wave and generating smaller particles with uniform size (Antonietti \& Landfester 2002).

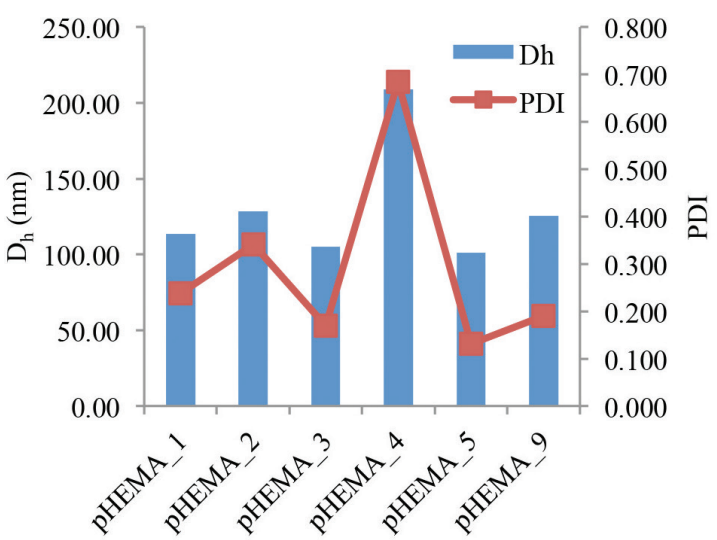

FIGURE 1. Hydrodynamic diameters $\left(\mathrm{D}_{\mathrm{h}}\right)$ and PDI of pHEMA_1 - pHEMA_5 and pHEMA_9 prepared at different sonication amplitudes $(10-60 \%)$ of 10 min sonication time

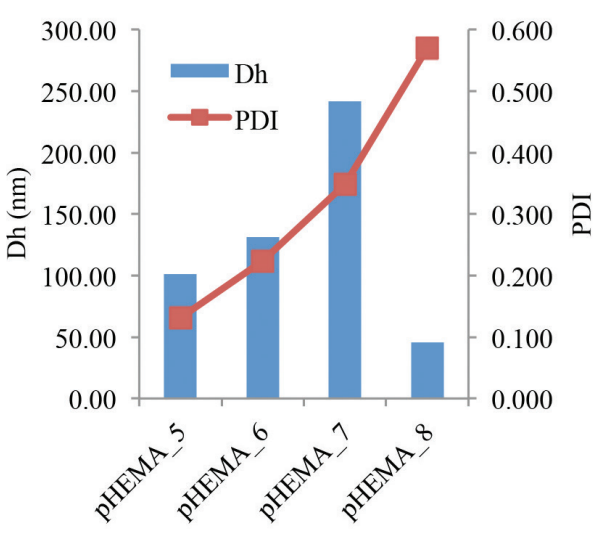

FIGURE 2. Hydrodynamic diameters $\left(\mathrm{D}_{\mathrm{h}}\right)$ and PDI of pHEMA_5 - pHEMA_8 prepared at 50\% sonication amplitude of different sonication times

However, at 50\% sonication amplitude, the particle sizes and PDI values of pHEMA nanoparticles were rising up with increasing of sonication time from 10 - $30 \mathrm{~min}$ (Figure 2) which contradicts from the theory. Although pHEMA_8 sample prepared at $30 \mathrm{~min}$ of sonication shows the smallest particle size $(46 \mathrm{~nm})$, however, the PDI value obtained is broad $(0.570)$. These results suggest that pHEMA_5 prepared at $10 \mathrm{~min}$ of sonication gives narrower PDI (0.131) and, hence, shows the optimum condition for $50 \%$ sonication amplitude series.

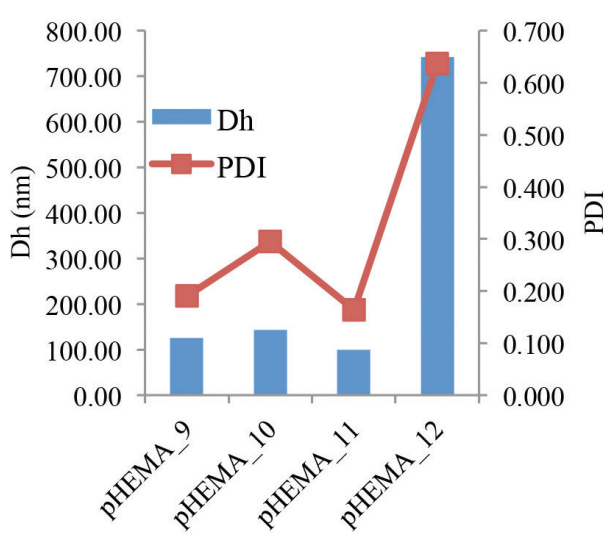

FIGURE 3. Hydrodynamic diameters $\left(\mathrm{D}_{\mathrm{h}}\right)$ and PDI of pHEMA 9 - pHEMA_12 prepared at $60 \%$ sonication amplitude of different sonication times

Meanwhile,pHEMA_11 prepared at $60 \%$ sonication amplitude shows the best result with particle size and PDI value of $100 \mathrm{~nm}$ and 0.164 , respectively (Figure 3). Among all of the pHEMA nanoparticles, pHEMA_5 and pHEMA_11 show optimum sonication conditions for producing polymer nanoparticles within desired size range which is between $50-500 \mathrm{~nm}$ (Capek 2010). It can be suggested that the most favorable energy requires to generate pHEMA nanoparticles rely between $50 \%-60 \%$ of sonication amplitude with $10-20$ min of sonication time. 


\section{FTIR ANALYSIS}

The formation of pHEMA nanoparticles were confirmed by FTIR spectroscopy (Figure 4). FTIR spectra of pHEMA nanoparticles (Figure 4) shows uniform broad intensity peaks in the range of $3400-3200 \mathrm{~cm}^{-1}$ due to the polymeric association of $\mathrm{O}-\mathrm{H}$ stretching vibration mode (Seven \& Sahiner 2014). The peaks in the range of $2935-2915 \mathrm{~cm}^{-1}$ are referred to aliphatic $\mathrm{C}-\mathrm{H}$ stretching bands (Holmes et al. 2011). Strong absorption band around $1740-1725 \mathrm{~cm}^{-1}$ are belonged to stretching carbonyl group (Bodas et al. 2005). It is worth noting that all pHEMA nanoparticles obtained at different sonication amplitude and times showed similar pattern of IR spectra, hence confirming the formation of polymer nanoparticles.

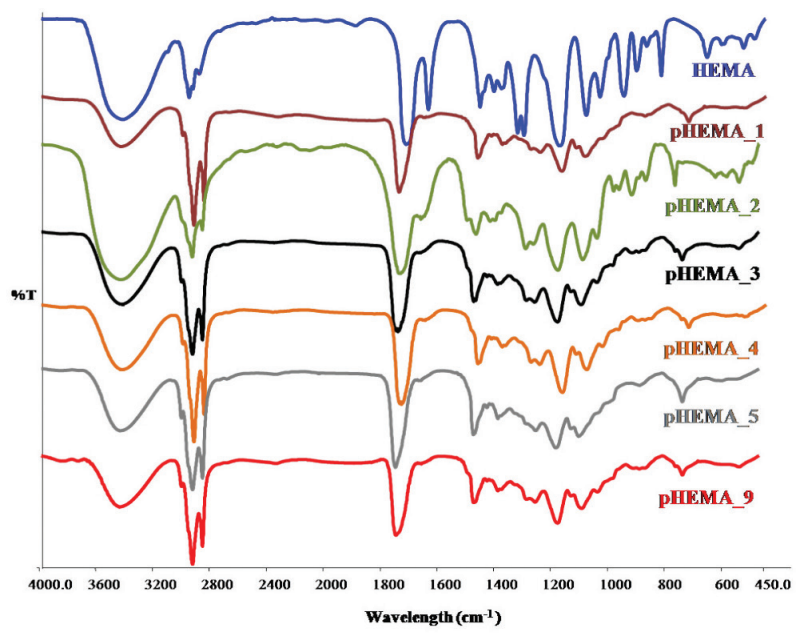

FIGURE 4. FTIR spectra of pHEMA 1 - pHEMA 9

\section{MORPHOLOGICAL ANALYSIS}

Selections of polymer nanoparticles were further analyzed by scanning electron microscope (SEM) and transmission electron microscope (TEM) to provide further insight into their morphology and average particle size. SEM image obtained from pHEMA_11 show the existence of aggregations with the average particle sizes were in a range of 4 - $5 \mu \mathrm{m}$ (Figure 5(a)). The aggregation of the polymer samples was expected to be observed under SEM on account of nature of sample preparation for SEM and during drying process of the samples. TEM image of pHEMA_11 is depicted in Figure 5(b). It can clearly be seen that pHEMA nanoparticles possess a spherical shape with average diameters measurements approximately 110 - $220 \mathrm{~nm}$, which are consistent with the mean diameter obtained from DLS. It is worth to mention that the average particle sizes of pHEMA nanoparticles obtain from TEM were determined by manually measure average diameter of each particle ( 30 particles) based on the scale bar.

\section{SOLUBILITY TEST}

Simple solubility test was conducted to determine the hydrophilicity of pHEMA nanoparticles. It was observed
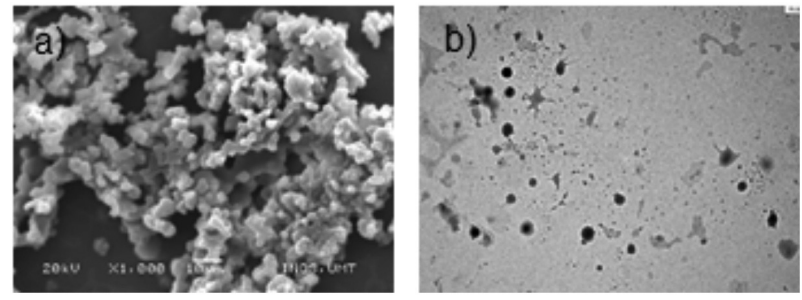

FIGURE 5. (a) SEM and (b) TEM image of pHEMA_11

that pHEMA_11 is swelled when firstly immersed in aqueous solution (Figure 6(a)). The ability of pHEMA nanoparticles to uptake and hold water content makes the size double from its original size. Interestingly, after two weeks,pHEMA_11 is partially dissolved in the aqueous media forming cloudy solution with small precipitates were observed (Figure 6(b)). This phenomenon is happened due to the fact that pHEMA has capability to absorb water on account of the presence of hydrophilic groups such as $-\mathrm{OH},-\mathrm{CONH}-,-\mathrm{CONH}_{2},-\mathrm{COOH}$ and $-\mathrm{SO}_{3} \mathrm{H}$. The main hydrophilic groups present in pHEMA are $-\mathrm{OH}$ and $-\mathrm{COOH}$, hence, when pHEMA is subjected to water for prolong time (after two weeks), it will swell due to the molecule's hydrophilic pendant group and has tendency to rupture and forming cloudy solution. a)

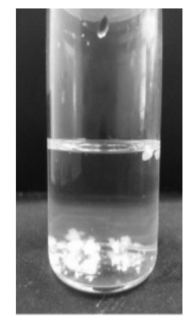

b)

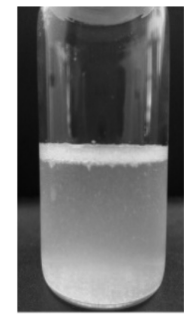

FIGURE 6 . The solubility test of pHEMA_11 after (a) firstly dissolved (b) 2 weeks dissolved in aqueous solution

\section{CONCLUSION}

Hydrophilic pHEMA nanoparticles were successfully synthesized via inverse miniemulsion polymerization technique. Sonication time and amplitude of inverse miniemulsion polymerization process give a significant effect towards average particle size and distribution of polymer nanoparticles as determined by DLS. The formation of polymer nanoparticles was confirmed by FTIR spectroscopy, and analysis of TEM images showed mean particle diameter of pHEMA nanoparticles is between $110-220 \mathrm{~nm}$. Solubility test indicates that pHEMA nanoparticles can slowly be dissolved in aqueous medium forming cloudy solution. It is expected that the engineered hydrophilic polymer nanoparticles could give huge benefits especially as a probe in medical or biological applications. 


\section{ACKNOWLEDGEMENTS}

We thanked the Ministry of Higher Education, Malaysia and Universiti Malaysia Terengganu for the funding (FRGS 59344 \& TAPE 55146) and generous support. We also would like to acknowledge Prof Misni Misran (Department of Chemistry, University of Malaya) for the helps in DLS.

\section{REFERENCES}

Antonietti, M. \& Landfester, K. 2002. Polyreactions in miniemulsions. Progress in Polymer Science 27(4): 689-757.

Bajpai, A.K., Shukla, S.K., Bhanu, S. \& Kankane, S. 2008. Responsive polymers in controlled drug delivery. Progress in Polymer Science 33: 1088-1118.

Bodas, D.S., Desai, S.M. \& Gangal, S.A. 2005. Desposition of plasma-polymerized hydroxhethyl methacrylate (HEMA) on silicon in presnce of argon plasma. Applied Surface Science 245: 186-190.

Cao, Z., Yang, L., Yan, Y., Shang, Y., Ye, Q., Qi, D., Zierner, U., Shan, G. \& Landfester, K. 2013. Fabrication of nanogel core-silica shell and hollow silica nanoparticles via an interfacial sol-gel process triggered by transition-metal salt in inverse systems. Journal of Colloid and Interface Science 406: $139-147$.

Capek, I. 2010. On inverse miniemulsion polymerization of conventional water-soluble monomers. Advances in Colloid and Interface Science 156(1-2): 35-61.

Chen, M. \& Yin, M. 2014. Design and development of fluorescent nanostructures for bioimaging. Progress in Polymer Science 39(2): 365-395.

Elbert, D.L. 2011. Liquid-liquid two-phase systems for the production of porous hydrogels and hydrogel microspheres for biomedical applications: A tutorial review. Acta Biomaterial 7(1): 31-56.

Faridi-Majidi, R., Sharifi-Sanjani, N. \& Agend, F. 2006. Encapsulation of magnetic nanoparticles with polystyrene via emulsifier-free miniemulsion polymerization. Thin Solid Films 515(1): 368-374.

Gao, Q., Wang, C., Liu, H., Wang, C., Liu, X. \& Tong, Z. 2009. Suspension polymerization based on inverse pickering emulsion droplets for thermo-sensitive hybrid microcapsules with tunable supracolloidal structures. Polymer 50(12): 2587-2594.

Gavasane, A.J. \& Pawar, H.A. 2014. Synthetic biodegradable polymers used in controlled drug delivery system: An overview. Clinical Pharmacology \& Biopharmaceutics 3(2): $1-7$.

Ghosh, P.K. 2000. Hydrophilic polymeric nanoparticles as drug carriers. Indian Journal of Biochemistry \& Biophysics 37: 273-282.

Gulsen, D. \& Chauhan, A. 2005. Dispersion of microemulsion drops in HEMA hydrogel: A potential ophthalmic drug delivery vehicle. International Journal of Pharmaceutics 292(1-2): 95-117.

Han, H., Zhang, S., Wang, Y., Chen, T., Jin, Q., Chen, Y., Li, A. \& Ji, J. 2016. Biomimetic drug nanocarriers prepared by miniemulsion polymerization for near-infrared imaging and photothermal therapy. Polymer 82: 255-261.

Harun, N.A., Horrocks, B.R. \& Fulton, D.A. 2011. Aminiemulsion polymerization technique for encapsulation of silicon quantum dots in polymer nanoparticles. Nanoscale 3(11): 4733-4741.
Holmes, R.L., Campbell, J.A., Linser, R., Hook, J.M. \& Burford, R.P. 2011. In situ preparation of poly(2-hydroxyethyl methacrylate)-titania hybrids using $\gamma$-radiation. Polymer 52: 4471-4479.

Ismail, Z., Kassim, S. \& Harun, N.A. 2017. Development of hydrophilic poly (N-vinylpyrrolidone) nanoparticles via inverse miniemulsion polymerization technique. AIP Conference Proceedings 1885(1): 020079.

Koul, V., Mohamed, R., Kuckling, D., Adler, H.J.P. \& Choudhary, V. 2011. Interpenetrating polymer network (IPN) nanogels based on gelation and poly(acrylic acid) by inverse miniemulsion technique: Synthesis and characterization. Colloids and Surfaces B: Biointerfaces 83(2): 204-213.

Mirzadeh, H., Katbab, A.A., Khorasani, M.T., Burford, R.P., Gorgin, E. \& Golestani, A. 1995. Cell attachment to laserinduced AAm and HEMA-grafted ethylene-propylene rubber as biomaterials: In vivo study. Biomaterials 16(8): 641-648.

Muthiah, M., Park, I.K. \& Cho, C.S. 2013. Surface modification of iron oxide nanoparticles by biocompatible polymers for tissue imaging and targeting. Biotechnology Advances 31(8): 1224-1236.

Oh, J.K., Bencherif, S.A. \& Matyjaszewski, K. 2009. Atom transfer radical polymerization in inverse miniemulsion: A versatile route toward preparation and functionalization of microgels/nanogels for tageted drug delivery applications. Polymer 50(19): 4407-4423.

Oh, J.K., Dong, H., Zhang, R., Matyjaszewski, K. \& Schlaad, H. 2007. Preparation of nanoparticles of double-hydrophilic PEO-PHEMA block copolymers by AGET ATRP in inverse miniemulsion. Journal of Polymer Science Part A: Polymer Chemistry 45(21): 4764-4772.

Oh, J.K., Tang, C., Gao, H., Tsarevsky, N.V. \& Krzysztof, M. 2006. Inverse miniemulsion ATRP: A new method for synthesis and functionalization of well-defined water-soluble/ cross-linked polymeric particles. Journal of the American Chemical Society 128(16): 5578-5584.

Pandey, S.K., Haldar, C., Patel, D.K. \& Maiti, P. 2013. Biodegradable polymers for potential delivery systems for therapeutics. In Multifaceted Development and Application of Biopolymers for Biology, Biomedicine and Nanotechnology, Advances in Polymer Science, edited by Dutta P. \& Dutta, J. Berlin, Heidelberg: Springer. Volume 254. pp. 169-202.

Rao, J.P. \& Geckeler, K.E. 2011. Polymer nanoparticles: Preparation techniques and size control parameters. Progress in Polymer Science 36(7): 887-913.

Richez, A.P., Yow, H.N., Biggs, S. \& Cayre, O.J. 2013. Dispersion polymerization in non-polar solvent: Evolution toward emerging applications. Progress in Polymer Science 38(6): 897-931.

Sarika, P.R., Anil Kumar, P.R., Raj, D.K. \& James, N.R. 2015. Nanogels based $\mathrm{n}$ alginic aldehyde and gelatin by inverse miniemulsion technique: Synthesis and characterization. Carbohydrate Polymers 119: 118-125.

Seven, F. \& Sahiner, N. 2014. Modified macroporous p(2hydroexyethyl methacrylate) (PHEMA) cryogel composites for $\mathrm{H}_{2}$ production from hydrolysis of $\mathrm{NaBH}_{4}$. Fuel Processing Technology 128: 394-401.

Srivastava, A., Yadav, T., Sharma, S., Nayak, A. \& Kumari, A. 2016. Polymers in drug delivery. Journal of Biosciences and Medicines 4: 69-84.

Tian, H., Tang, Z., Zhuang, X., Chen, X. \& Jing, X. 2012. Biodegradable synthetic polymers: Preparation, 
functionalization and biomedical application. Progress in Polymer Science 37(2): 237-280.

Tomar, N., Tomar, M., Gulati, N. \& Nagaich, U. 2012. pHEMA hydrogels: Devices for ocular drug delivery. International Journal of Health \& Allied Sciences 1(4): 224-230.

Xu, Z.Z., Wang, C.C., Yang, W.L., Deng, Y.H. \& Fu, S.K. 2004. Encapsulation of nanosized magnetic iron oxide by polyacrylamide via inverse miniemulsion polymerization. Journal of Magnetism and Magnetic Materials 277: 136-143.

Yildiz, U. \& Landfester, K. 2008. Miniemulsion polymerization of styrene in the presence of macromonomeric initiators. Polymer 49(23): 4930-4934.

Zalikha Ismail \& Noor Aniza Harun* Faculty of Science \& Marine Environment Universiti Malaysia Terengganu 21030 Kuala Nerus, Terengganu Darul Iman Malaysia
Noor Aniza Harun*

Advance NanoMaterials (ANOMA) Research Group

Universiti Malaysia Terengganu

21030 Kuala Nerus, Terengganu Darul Iman Malaysia

*Corresponding author; email: nooraniza@umt.edu.my

Received: 7 February 2019

Accepted: 26 May 2019 